\title{
Identification of a lymphocyte minor histocompatibility antigen in Mauritian cynomolgus macaques
}

Jason T. Weinfurter, ${ }^{a}$ Michael E. Graham, ${ }^{b^{*}}$ Adam J. Ericsen, ${ }^{\star \star *}$ Lea M. Matschke, ${ }^{a}$ Sian Llewellyn-Lacey, ${ }^{c}$ David A. Price, ${ }^{c, d}$ Roger W. Wiseman, ${ }^{b}$ Matthew R. Reynolds ${ }^{a, b}$

a Department of Pathobiological Sciences, School of Veterinary Medicine, University of Wisconsin-Madison, Madison, Wisconsin, USA

${ }^{b}$ Wisconsin National Primate Research Center, University of Wisconsin-Madison, Madison, Wisconsin, USA

${ }^{c}$ Division of Infection and Immunity, Cardiff University School of Medicine, Cardiff, Wales, United Kingdom.

D Systems Immunity Research Institute, Cardiff University School of Medicine, Cardiff, Wales, UK

Running Head: A macaque minor histocompatibility antigen in APOBEC3C \# Address correspondence to Matthew R. Reynolds, matt.reynolds@wisc.edu

* Present address: Wisconsin Energy Institute, University of Wisconsin-Madison, Madison, Wisconsin, USA

${ }^{* *}$ Present address: Yerkes National Primate Research Center, Emory University, Atlanta, Georgia, USA

Word count text: 2,652

Word count abstract: 181 


\begin{abstract}
Allogeneic hematopoietic stem cell transplantation can lead to dramatic reductions in human immunodeficiency virus (HIV) reservoirs. This effect is mediated in part by donor T cells that recognize lymphocyte-expressed minor histocompatibility antigens (mHAgs). The potential to mark malignant and latently infected cells for destruction makes mHAgs attractive targets for cellular immunotherapies. However, testing such HIV reservoir reduction strategies will likely require preclinical studies in nonhuman primates (NHPs). In this study, we used a combination of alloimmunization, whole exome sequencing, and bioinformatics to identify a mHAg in Mauritian cynomolgus macaques (MCMs). We mapped the minimal optimal epitope to a 10-mer peptide (SW10) in apolipoprotein B mRNA editing enzyme catalytic polypeptide-like 3C (APOBEC3) and determined the major histocompatibility complex class I restriction element as Mafa-A1*063, which is expressed in almost $90 \%$ of MCMs. APOBEC3C SW10-specific CD8+ T cells recognized immortalized B cells but not fibroblasts from a mHAg positive MCM. These results collectively provide a framework for identifying mHAgs in a nontransplant setting and suggest that APOBEC3C SW10 could be used as a lymphocyte-restricted model antigen in NHPs to test various mHAg-targeted immunotherapies.
\end{abstract}




\section{Importance}

Cellular immunotherapies developed to treat blood cancers may also be effective against latent HIV. Preclinical studies of such immunotherapies are hindered by a lack of known target antigens. We used a combination of alloimmunization, basic immune assays, whole exome sequencing, and bioinformatics to identify a lymphocyte-restricted minor histocompatibility antigen in a genetically related population of nonhuman primates. This minor histocompatibility antigen provides an actionable target for piloting cellular immunotherapies designed to reduce or eliminate latent reservoirs of HIV. 


\section{Background}

The establishment of long-lived viral reservoirs after primary infection is a major obstacle to the development of curative therapies for human immunodeficiency virus (HIV) (1-4). These latent reservoirs are unaffected by antiretroviral therapy (ART) and readily reactivate upon cessation of treatment $(5,6)$. Moreover, it has been estimated that latently infected cells, which exist at low frequencies in vivo, would only decay to extinction after more than 60 years in the presence of continuous $\operatorname{ART}(2,7)$. Strategies are therefore being developed to reduce or eliminate viral reservoirs and attain sustained ART-free remission $(8,9)$.

Dramatic reductions in latent viral reservoirs have been observed in HIV positive patients with hematological malignancies undergoing treatment with allogeneic hematopoietic stem cell transplants (allo-HSCTs). In two widely publicized cases, the "Berlin" and "London" patients achieved ART-free remission after receiving allo-HSCTs from donors homozygous for the CCR5 $\Delta 32$ gene mutation $(10,11)$. The absence of functional CCR5 co-receptors on the surface of donor-derived immune cells is undoubtedly a crucial factor in the remarkable success of these interventions, preventing the reseeding of the newly established hematopoietic system. However, graft-versus-host (GvH) responses likely contributed to the elimination of endogenous viral reservoirs $(10,12)$. Interestingly, the London patient received reduced-intensity conditioning prior to alloHSCT, leaving a residual pool of cancerous and HIV latently infected cells $(10,13)$. In this setting, allogeneic T cell responses potentially eliminated both malignant and latently infected cells by simultaneously mediating "graft-versus-leukemia" and "graft-versus-HIV" effects. Intriguingly, similar reductions in latent viral reservoirs have been achieved using 
HSCs from donors expressing wild-type CCR5 (14-16). The most notable examples are the "Boston" patients, who received allo-HSCTs under cover of ART and exhibited prolonged ART-fee remission before viral rebound (14). Collectively, these anecdotal cases demonstrate that alloreactive T cells can attack and destroy endogenous hematopoietic cells latently infected with HIV.

Alloreactive T cells commonly recognize minor histocompatibility antigens (mHAgs). mHAgs are polymorphic peptides presented by major histocompatibility complex (MHC) molecules and recognized as "foreign" by allogeneic T cells (17). The tissue distribution and expression profile of $\mathrm{mHAg}$-encoding genes affect the outcome of $\mathrm{GvH}$ responses (18, 19). Expression of mHAgs across a broad range of tissues can result in toxic $\mathrm{GvH}$ reactions and potentially fatal $\mathrm{GvH}$ disease (GvHD). Conversely, mHAgs presented exclusively by recipient leukocytes, including malignant and latently infected cells, can elicit beneficial $\mathrm{GvH}$ responses that eliminate tumors and latently infected cells alike. Immunotherapies targeting leukocyte-derived mHAgs may therefore provide a novel approach to eliminating hematopoietic cells latently infected with HIV. Further studies are required to advance this concept, however, and the potential efficacy of graft-versus-HIV responses can only realistically be assessed in nonhuman primates (NHPs) (20).

Nonhuman primates (NHP) are common models in preclinical organ transplant and infectious disease studies. Despite their ubiquitous use in research, no mHAgs have been identified in NHPs. In contrast, several approaches have been used to identify various human mHAgs including peptide elution, cDNA library screens, and genetic linkage analyses using large panels of immortalized B cells (21). Recently, these labor-intensive 
methods have been complemented by advances in next-generation sequencing technologies to accelerate the pace of mHAg discovery (22).

Most outbred populations of NHPs are genetically diverse, making it challenging to identify cohorts of animals with one or more matches at the MHC class I (MHC-I) locus. In contrast, Mauritian-origin cynomolgus macaques (MCM) are descended from a small founder population approximately 400 years ago (23), resulting in limited genetic diversity, even within highly polymorphic loci (24-26). Indeed, only seven major MHC haplotypes, designated M1 through M7, have been identified in MCMs.

The unique population genetics of MCM provides an opportunity to map mHAgs in a relevant NHP transplant and HIV cure model. In this report, we describe the identification and characterization of a mHAg, APOBEC3C SW10, in MCM. This epitope is restricted by the MHC- I molecule Mafa-A1*063, which is expressed by almost $90 \%$ of MCMs (27). Our data suggests that the APOBEC3C SW10 may serve as a useful model antigen for interventional studies of mHAg-targeted therapies in NHPs.

\section{Results}

\section{Generation of mHAg-specific $\mathrm{CD}^{+} \mathrm{T}$ cell clones}

We identified $21 \mathrm{MCM}$ heterozygous for the M1 and M2 MHC haplotypes (M1/M2). mHAgreactive $\mathrm{T}$ cells were stimulated in vivo by alloimmunizing four M1/M2 MCMs (vaccinees) with a mixture of peripheral blood mononuclear cells (PBMC) from four MHC-identical MCM (donors). Allo-reactive T cells were then isolated by incubating PBMCs from the vaccinees with a mixture of irradiated immortalized donor B lymphoblastoid cell lines 
(BLCLs). After 3 weeks, these T-cell lines reacted to allogeneic but not autologous BLCLs in IFN-y ELISpot assays, indicating specific recognition of donor-restricted mHAgs.

To identify individual mHAgs, we isolated T cell clones via limiting dilution of the alloreactive T cell lines. After 8 weeks in culture, these T cell clones $(n=60)$ displayed unique patterns of binary reactivity against a panel of MHC-matched allogeneic BLCLs $(n=10)$ in IFN-y ELISpot assays, indicating specific recognition of distinct mHAgs (Figure 1). These reactivity patterns were used to identify genomic polymorphisms associated with potential mHAgs.

\section{Identification of mHAg-associated SNPs in APOBEC3C}

We reasoned that comparing the genomic sequences of MCM whose BLCLs were or were not recognized by alloreactive T cell clones would simplify the winnowing of germline polymorphisms associated with mHAgs. Accordingly, we performed whole exome sequencing (WES) using a probe set specially designed to capture MCM coding sequences, which enabled the generation of single nucleotide polymorphism (SNP) profiles for each MCM. Using a custom-built analysis tool, we then parsed the WES data for non-synonymous SNPs (ns-SNPs) that distinguished T cell clone-specific mHAg ${ }^{\text {pos }}$ and $\mathrm{mHAg}^{\text {neg }}$ groups of BLCLs. We prioritized ns-SNPs present only in the $\mathrm{mHAg}^{\text {pos }}$ group for further analysis, surmising these ns-SNPs likely encoded the relevant mHAgs.

We focused our mHAg mapping efforts on the ns-SNPs associated with T cell clones 2, 4, 11, and 14. The segregation analysis identified SNPs encoding amino acid polymorphisms in the IGHM, OR4K3, APOBEC3C, and IL20RA/MAP3K5 genes. For each candidate mHAg, we identified the 11 amino acids upstream and the 11 amino acids 
downstream of the corresponding SNPs and synthesized 15-mer peptides overlapping by 11 amino acids. Each 15-mer peptide was then pulsed onto $\mathrm{mHAg}^{\text {neg }}$ BLCLs at a concentration of $1 \mu \mathrm{M}$ and incubated with their respective T cell clone. In IFN-ץ ELISpot assays, T cell clone 11 (T11) strongly recognized two of the three 15-mers containing an arginine-to-leucine amino acid change, relative to the $\mathrm{mHAg}{ }^{\text {neg }}$ sequence, in APOBEC $3 \mathrm{C}$ (Figure 2A). The other 15-mer peptides failed to elicit IFN-y production in parallel assays with $\mathrm{T} 2$, $\mathrm{T} 4$, or T14. We therefore concentrated on identifying the minimal optimal epitope recognized by $\mathrm{T} 11$.

\section{Identification of the minimal optimal mHAg epitope in APOBEC3C}

We reasoned that the $\mathrm{mHAg}$ epitope recognized by $\mathrm{T} 11$ was present in each of the two stimulatory APOBEC3C 15-mer peptides, denoted as A3C-A and A3C-B, but not in the non-stimulatory APOBEC3C 15-mer peptide, denoted as A3C-C (Figure 2B). Accordingly, we synthesized a series of overlapping 8-mer, 9-mer, 10-mer, and 11-mer peptides spanning the 11 amino acids present in $A 3 C-A$ and $A 3 C-B$ to map the minimal optimal epitope in APOBEC3C. We also synthesized a 15-mer and 11-mer peptide matching the reference, "wild-type", sequence with an arginine replacing the variant leucine (Figure 2B). In intracellular cytokine staining (ICS) assays, a bulk T cell line generated against A3C-A and A3C-B strongly recognized the 11-mer peptide LW11, which matched the intersecting region of the overlapping 15-mer peptides (Figure 3). A similar response was observed with the 10-mer peptide SW10. In contrast, weaker responses were observed with all other peptides, including LT10 and the wild-type peptides, which induced IFN-y production from approximately a third as many T cells as the corresponding variant peptides. 
To confirm these results, we conducted similar ICS assays using serial dilutions of each peptide that elicited a response at a concentration of $1 \mu \mathrm{M}$, namely LL8, ST9, LT10, SW10, and LW11. Sharp reductions in IFN-y were observed with decreasing concentrations of peptides LL8, ST9, and LT10 (Figure 4A). In contrast, SW10 and LT11 elicited similar levels of IFN-y production throughout the dilution series, which extended down to $1 \mathrm{nM}$. In further titration experiments, SW10 and LT11 exhibited largely equivalent dose-response curves down to a concentration of $1 \mathrm{fM}$, but SW10 elicited more potently at concentrations of $1 \mathrm{nM}$ and $100 \mathrm{pM}$, suggesting this peptide was the minimal optimal mHAg epitope in APOBEC3C (Figure 4B).

\section{MHC class I restriction of the mHAg epitope in APOBEC3C}

To determine the restricting MHC-I molecule for APOBEC3C SW10, we used three immortalized human MHC-I null cell lines individually expressing Mafa-A and Mafa-B allomorphs from the MCM M2 MHC haplotype (28). Each of these MHC-I "transferents" was pulsed with the SW10 peptide and incubated with the APOBEC3C-specific T cell line. In ICS assays, only the T cells incubated with the peptide-pulsed Mafa-A $1{ }^{*} 063$ transferent induced IFN-y production above background levels, indicating stable complexes with SW10 (Figure 5).

The SW10 epitope corresponds to the previously described Mafa-A1*063 peptidebinding motif, with a serine at position one, a proline at position two, an asparagine at position three, and a tryptophan at the carboxy terminus of the peptide $(24,29)$. We were therefore able to form tetrameric complexes of Mafa-A ${ }^{*} 063 / \mathrm{SW} 10$. In line with the 
functional data, these recombinant antigen complexes robustly stained APOBEC3Cspecific T cells, confirming Mafa-A1*063 as the restricting element for SW10 (Figure 6).

\section{Tissue distribution of the APOBEC3C mHAg epitope}

The tissue distribution of mHAgs can be exploited for therapeutic gain (30). This strategy is epitomized by the infusion of allogeneic T cells to treat hematologic cancers, which operates via the selective targeting of mHAgs expressed by recipient leukocytes, including malignant cells, to eliminate tumors without causing severe GvHD. We therefore sought to determine whether immune recognition of the SW10 epitope is similarly limited to the hematopoietic system, given that $\mathrm{CD} 4^{+} \mathrm{T}$ cells are known to express high levels of APOBEC3C.

To test nonhematopoietic cells, we collected skin explants and isolated fibroblasts from the APOBEC3C SW10 ${ }^{\text {pos }}$ MCM, cy0743. In IFN-y ELISpot assays, SW10-specific T cell lines isolated from the alloimmunized MCMs cy0738 and cy0747 displayed greater reactivity against the $\mathrm{mHAg}^{\text {pos }} \mathrm{BLCL}$ from cy0743 compared with either the corresponding autologous BLCLs or mHAg ${ }^{\text {pos }}$ fibroblasts from cy0743, suggesting limited expression of SW10 outside the hematopoietic system (Figure 7). The APOBEC3C SW10 epitope may therefore serve as a model hematopoietic tissue-restricted antigen in MCMs.

\section{Frequency of the SW10-encoding SNP in $68 \mathrm{MCM}$}

To determine the overall prevalence of the SW10-encoding SNP, irrespective of MHC haplotype, we expanded our analysis to include an additional $47 \mathrm{MCMs}$. Across the entire WES dataset, five animals had a SNP at position NC_027902.1:80990325 in 
$A P O B E C 3 C$, representing a population frequency of $7.35 \%$ among $68 \mathrm{MCMs}$. Four

animals had the G->T polymorphism at this position, encoding the leucine variant found in SW10. The other animal had a G->A nucleotide polymorphism at this position, encoding glutamine, which although not tested in this study, may similarly induce alloreactive T-cell responses in Mafa-A1*063-positive MCMs.

\section{Discussion}

In this study, we used a combination of alloimmunization, WES, and bioinformatics to identify a mHAg in MCMs. Although a previous study described the conservation of human $\mathrm{HA}-1, \mathrm{HA}-2$, and $\mathrm{H}-\mathrm{Y}$ mHAgs in chimpanzees and rhesus macaques (31), the epitope identity and immunogenicity of these mHAgs was not confirmed in vivo. Accordingly, the SW10 epitope in APOBEC represents the first clearly defined mHAg in NHPs.

Our investigation was made possible by the unique genetics of MCMs. In contrast to most outbred populations, MCMs passed through an artificial bottleneck approximately 400 years ago $(32,33)$, which resulted in a $23 \%$ reduction in the number of SNPs $(33)$ and limited MHC diversity compared with mainland cynomolgus macaques $(26,27)$. These genetic peculiarities made it possible to assemble $21 \mathrm{MHC}$-identical animals, subdivide them into discrete groups based on mHAg expression, and map the SW10 epitope following the identification of SNPs in APOBEC3C.

Fortuitously, the MHC class I allomorph Mafa-A1*063 restricts APOBEC3C SW10. Mafa- $A 1^{*} 063$ is a "universal" A locus MHC-I allele expressed by the three most common MCM MHC haplotypes (M1, M2, and M3) (27). As a result, approximately $88 \%$ of MCMs have the potential to present APOBEC3C SW10. However, the SNP encoding this mHAg 
is present at a much lower frequency, estimated at only $\sim 7 \%$ based on our analysis of 68 MCMs. Ideally, this SNP would be present at a higher frequency for ease of study. It should be noted that similar frequency limitations apply to MHC-homozygous MCMs (26). Although potentially limiting in the context of future interventional studies, breeding programs could be established to increase the frequency of APOBEC SW10 mHAg ${ }^{\text {pos }}$ MCMs.

$A P O B E C 3 C$ belongs to a family of well-known restriction factors that limit the replication of HIV and SIV. Apolipoprotein B mRNA editing enzyme catalytic polypeptidelike 3 (APOBEC) proteins are cytidine deaminases that protect against endogenous retroelements, retroviruses, and lentiviruses by inducing the hypermutation of viral genomes during reverse transcription (34). APOBEC3 genes are expressed widely in immune cells (35-37). In line with these gene expression studies, we found that APOBEC3C SW10-specific T cells recognized BLCLs but not fibroblasts isolated from a $\mathrm{mHAg}^{\text {pos }} \mathrm{MCM}$. However, $A P O B E C 3 C$ is also expressed in a variety of human tissues, including the gut and the lungs $(36,37)$. The corresponding tissues may therefore be susceptible to attack by APOBEC3C SW10-specific T cells in MCMs. Our analysis nonetheless mirrors the screening process used to select tissue-restricted mHAg-specific T cell clones for infusion into patients with refractory leukemia (38), suggesting that the APOBEC3C SW10 epitope is sufficiently tissue-restricted to minimize the risk of severe GvHD in MCMs.

T cell immunotherapy is a useful and often curative strategy for treating hematologic cancers (38-47). A similar approach could potentially be used to target latent reservoirs of HIV $(48,49)$. Such reservoirs are limited to immune cells and are thought to be reduced or 
even eliminated by $\mathrm{GvH}$ responses after allo-HSCT (10-12). However, it is difficult to test this hypothesis in humans, because very few HIV+ patients undergo allo-HSCT. Moreover, different conditioning regimens are typically used in these rare cases, and efficacy likely depends to some extent on the receipt of HSCs with homozygous expression of CCR5 $\Delta 32$. Our results may therefore facilitate the development of standardized models to investigate the antiviral effects of GvH responses in NHPs.

Our immunization strategy was adapted from human clinical trials investigating paternal lymphocyte immunotherapy (LIT) as a treatment for recurrent miscarriages (50, 51). In these studies, LIT was well tolerated and did not increase the risk of autoimmunity or GvHD $(52,53)$. In MHC-matched individuals, this alloimmunization strategy likely enriches for T cells targeting mHAgs expressed by leukocytes and could feasibly be extended to map mHAgs in other species, like outbred macaques or humans. Such in vivo enrichment protocols may offer advantages over traditional in vitro approaches for the identification of immunodominant mHAgs (54-57).

Further refinements to the methods described here could expedite the identification of mHAgs. A key limitation in our study was the inefficient generation of BLCLs. Although we generated WES data from $21 \mathrm{MHC}$-identical MCMs, we were only able to immortalize B cells from 10 animals, which constrained our ability to sieve candidate SNPs. The inclusion of a statistical component in the WES segregation analysis would also have likely enhanced the identification and prioritization of candidate SNPs (56). In addition, we focused our analysis on coding regions, which preclude the capture of intron-located or splice variant-generated SNPs (58). Whole-genome sequencing and/or mass 
spectrometric approaches would circumvent this particular limitation and allow the identification of such "cryptic" mHAgs.

In conclusion, we have identified a mHAg epitope in APOBEC3C restricted by the common MCM MHC-I allomorph Mafa-A1*063. Importantly, allorecognition of this epitope appeared to be limited to cells of hematopoietic origin, suggesting potential utility as a model antigen for testing mHAg-targeted immunotherapies in NHPs. In particular, we anticipate our discovery will allow the systematic analysis of $\mathrm{GvH}$ responses in the context of therapeutic interventions designed to combat latent immunodefficiency viruses, which are readily modeled in MCMs.

\section{Acknowledgments}

We thank the veterinary staff at the Wisconsin National Primate Research Center (WNPRC) for their assistance. This study was funded by the National Institutes of Health (NIH) via grants R01 Al118495 and R24 OD021322 awarded to M.R.R. Additional support was provided by the Office of Research Infrastructure Programs/ OD via grant P51OD011106 awarded to the WNPRC at the University of Wisconsin-Madison. This research was conducted in part at a facility constructed with support from the Research Facilities Improvement Program via grants RR15459-01 and RR020141-01. D.A.P was supported by a Wellcome Trust Senior Investigator Award (100326/Z/12/Z). The funders had no role in study design, collection, analysis, interpretation of the data, or manuscript preparation. The content is solely the responsibility of the authors and does not necessarily represent the official views of the NIH. 


\section{Author contributions}

Jason T. Weinfurter performed experiments, acquired and analyzed data, and wrote the manuscript. Michael E. Graham and Adam J. Ericsen performed whole exome segregation analysis. Lea M. Matschke acquired and analyzed data. Sian LlewellynLacey and David A. Price generated the Mafa-A1*063/SW10 tetramer. Roger W. Wiseman contributed to sample preparation and study methodology. Matthew R. Reynolds acquired funding, conceived and directed the project, and wrote the manuscript. All authors edited the manuscript and approved the final version.

\section{Conflict of Interest Statement}

The authors have no conflicting financial interests.

\section{Materials and Methods}

\section{Ethics statement and animal care}

Cynomolgus macaques (Macaca fascicularis) used in this study were cared for by the staff at the Wisconsin National Primate Research Center according to the regulations and guidelines of the University of Wisconsin Institutional Animal Care and Use Committee, which approved this study (protocol g00695) in accordance with the recommendations of the Weatherall Report and the principles described in the National Research Council's Guide for the Care and Use of Laboratory Animals. Macaques were housed in enclosures with at least $4.3,6.0$, or 8.0 sq. ft. of floor space, measuring 30,32 , or 36 inches high and 
containing a tubular polyvinyl-chloride or stainless-steel perch. Each enclosure was equipped with a horizontal or vertical sliding door, an automatic water lixit, and a stainlesssteel feed hopper. Macaques were fed twice daily using a nutritional plan based on recommendations published by the National Research Council. Feeding strategies were individually tailored to the age and physical condition of each animal. Carbohydrate, energy, fat, fiber (10\%), mineral, protein, and vitamin requirements were provided in an extruded dry diet (2050 Teklad Global 20\% Protein Primate Diet). Dry diets were supplemented with fruits, vegetables, and other edible objects (e.g., nuts, cereals, seed mixtures, yogurt, peanut butter, popcorn, and marshmallows) to provide variety to the diet and to inspire foraging and other species-specific behaviors. To further promote psychological well-being, macaques were provided with food enrichment, human-tomonkey interaction, structural enrichment, and manipulanda. Environmental enrichment objects were selected to minimize the chances of pathogen transmission from one animal to another and from animals to care staff. Macaques were evaluated by trained animal care staff at least twice daily for signs of pain, distress, and illness by observing appetite, stool quality, activity level, and physical condition. Animals presenting abnormally for any of these clinical parameters were provided with appropriate care by attending veterinarians. Macaques were sedated with ketamine before each experimental procedure, and reversed with atipamezole after each experimental procedure. Animals were monitored regularly until fully recovered from anesthesia. 
PBMCs were separated from EDTA-anticoagulated blood ia density gradient centrifugation using Ficoll-Paque PLUS (GE Healthcare). Freshly isolated PBMCs from four donor M1/M2 MCM were pooled and resuspended in RPMI-1640 containing $10 \%$ fetal calf serum (FCS; R10) and $5 \mathrm{ug} / \mathrm{ml}$ phytohemagglutinin-P (Sigma-Aldrich). The culture was incubated overnight at $37^{\circ} \mathrm{C}$ in a $5 \% \mathrm{CO}_{2}$ atmosphere. Activated PBMCs were harvested the following morning, washed twice with phosphate-buffered saline (PBS), resuspended in PBS, and loaded into tuberculin syringes. Each macaque was then immunized with up to $4 \times 10^{7}$ activated PBMCs as described previously (59).

\section{Growing bulk $T$ cell lines to potential mHAgs}

mHAg-specific T cell lines were generated from cryopreserved PBMCs isolated from alloimmunized macaques and thawed as described previously (60). Briefly, 5x106 PBMCs were combined with $5 \times 10^{6}$ irradiated BLCLs from MHC-identical donor MCMs in $5 \mathrm{ml}$ of RPMI-1640 containing 15\% FCS (R15) and $10 \mathrm{ng} / \mathrm{ml}$ recombinant human IL-7 (R\&D Systems). Cultures were supplemented 2 days later with $1.25 \mathrm{ml}$ of R15 containing 100 $\mathrm{U} / \mathrm{ml}$ recombinant human IL-2 (R\&D systems; R15-100). R15-100 was added every 2 to 3 days thereafter, and T cell lines were stimulated weekly with equal numbers of irradiated BLCLs from MHC-identical donor MCMs. Peptide-specific T cell lines were grown similarly using autologous irradiated BLCLs pulsed with 15-mers A3C-1 and A3C-B (GenScript).

\section{Limiting dilution cloning}

Bulk T cell lines were counted with Trypan Blue exclusion dye and suspended at $1 \mathrm{cell} / \mathrm{ml}$ in R15-100. Each line was distributed across three 96-well plates at a mean of 0.2 
cells/well and placed at $37^{\circ} \mathrm{C}$ in a $5 \% \mathrm{CO}_{2}$ incubator. T cell clones were fed twice weekly by replacing half of the media volume with R15-100 and restimulated periodically with a mixture of irradiated MHC-identical donor BLCLs.

\section{ELISpot assays}

ELISpot assays were performed using precoated monkey IFN-ץ ELISpot ${ }^{\text {PLUS Kits }}$ according to the manufacturer's instructions (Mabtech). Briefly, 5,000 clonal T cells and 5,000 fibroblasts or BLCLs derived from individual MHC-identical animals were added to each well in a total of 200 ul of R10. Positive control wells contained concanavalin A (Sigma-Aldrich). Alternatively, 5,000 bulk T cells and 5,000 fibroblasts or BLCs derived from individual MHC-identical animals were added to each well in $200 \mu$ of R10. Positive control wells contained autologous BLCLs and the APOBEC3C SW10 peptide. All tests were performed in triplicate. Plates were incubated overnight at $37^{\circ} \mathrm{C}$ in a $5 \% \mathrm{CO}_{2}$ atmosphere and imaged using an AID ELISpot Reader (Autoimmun Diagnostika GmbH). Differences in the number of IFN-y spot-forming cells (SFCs) after stimulation with allogeneic versus autologous fibroblasts or BLCLs were assessed for significance using a one-way ANOVA with Tukey's test for multiple comparisons in Prism version 5.0 (GraphPad Software Inc.).

\section{Mapping the APOBEC3C SW10 epitope}

The mHAg epitope in APOBEC3C was mapped using a T cell line generated from an alloimmunized MCM in the presence of autologous irradiated BLCLs pulsed with the 15mer peptides A3C-A and A3C-B (Genescript). The minimal optimal epitope was 
determined using overlapping 8-mer, 9-mer, 10-mer, and 11-mer peptides (Genescript). Briefly, 100,000 mHAg ${ }^{\text {neg }}$ BLCLs were incubated for 1 hour with each peptide at a final concentration of $1 \mathrm{uM}$ and washed twice with R10. Next, 100,000 cells from the APOBEC3C T cell line were added to each tube in R10 containing $10 \mathrm{ug} / \mathrm{ml}$ brefeldin A (Sigma-Aldrich). Cells were then incubated for 5 hours at $37^{\circ} \mathrm{C}$ in a $5 \% \mathrm{CO} 2$ atmosphere, washed twice with PBS, and stained with LIVE/DEAD Fixable Near-IR dye according to the manufacturer's instructions (Thermo Fisher Scientific). To identify peptide-specific responses, cells were washed with $\mathrm{R} 10$, stained for 30 minutes at room temperature with anti-CD3 Alexa 700 (clone SP34-2; BD Biosciences) and anti-CD8 Pacific Blue (clone RPA-T8; BD Biosciences), washed twice with PBS containing 2\% FCS (FACS buffer), fixed in $1 \%$ paraformaldehyde (PFA), permeabilized in FACS buffer containing $0.1 \%$ saponin, and stained for 1 hour at room temperature with IFN-y FITC (clone 4S.B3; BD Biosciences). Cells were then washed twice with FACS buffer and resuspended in 1\% PFA. Targeted peptides were assayed similarly across a range of concentrations to identify the most immunogenic epitope. Data were acquired using an LSRII flow cytometer (BD Biosciences) and analyzed using FlowJo software version 10 (FlowJo LLC).

\section{Segregation analysis}

Segregation analysis was performed using a custom-built OSX application entitled Variant Segregator. This tool provides a user interface for setting up comparison groups, which allows the interrogation of multiple sample groups without the need to generate filtered vcf files using command line tools. The Variant Segregator identifies candidate SNPs using a simple scoring system that compares each animal in the $\mathrm{mHAg}^{\text {pos }}$ and $\mathrm{mHAg}{ }^{\text {neg }}$ groups to 
the Mmul-8.0.1 rhesus macaque reference genome. The scoring system assigns 5 points for each macaque with a homozygous SNP mismatch relative to the reference genome, 3 points for heterozygous SNP mismatches, and 0 points for homozygous SNP matches. The final segregation score is the point sum in the $\mathrm{mHAg}^{\text {pos }}$ group minus the point sum in the $\mathrm{mHAg}{ }^{\text {neg }}$ group. The segregation scores were used to identify and prioritize SNPs present in $\mathrm{mHAg}^{\text {pos }} \mathrm{MCMs}$ for further analysis. 


\section{References}

1. Chun, TW, Stuyver, L, Mizell, SB, Ehler, LA, Mican, JA, Baseler, M, Lloyd, AL,

Nowak, MA, Fauci, AS. 1997. Presence of an inducible HIV-1 latent reservoir during highly active antiretroviral therapy. Proc Natl Acad Sci U S A 94:13193-13197.

2. Finzi, D, Blankson, J, Siliciano, JD, Margolick, JB, Chadwick, K, Pierson, T, Smith, K, Lisziewicz, J, Lori, F, Flexner, C, Quinn, TC, Chaisson, RE, Rosenberg, E, Walker, B, Gange, S, Gallant, J, Siliciano, RF. 1999. Latent infection of CD4+ T cells provides a mechanism for lifelong persistence of HIV-1, even in patients on effective combination therapy. Nat Med 5:512-517.

3. Sengupta, S, Siliciano, RF. 2018. Targeting the Latent Reservoir for HIV-1. Immunity 48:872-895.

4. Wong, JK, Hezareh, M, Günthard, HF, Havlir, DV, Ignacio, CC, Spina, CA, Richman, DD. 1997. Recovery of replication-competent HIV despite prolonged suppression of plasma viremia. Science 278:1291-1295.

5. Chun, TW, Davey, RTJ, Engel, D, Lane, HC, Fauci, AS. 1999. Re-emergence of HIV after stopping therapy. Nature 401:874-875.

6. Davey, RT, Bhat, N, Yoder, C, Chun, TW, Metcalf, JA, Dewar, R, Natarajan, V, Lempicki, RA, Adelsberger, JW, Miller, KD, Kovacs, JA, Polis, MA, Walker, RE, Falloon, J, Masur, H, Gee, D, Baseler, M, Dimitrov, DS, Fauci, AS, Lane, HC. 1999. HIV-1 and T cell dynamics after interruption of highly active antiretroviral therapy (HAART) in patients with a history of sustained viral suppression. Proc Natl Acad Sci U S A 96:15109-15114. 
7. Crooks, AM, Bateson, R, Cope, AB, Dahl, NP, Griggs, MK, Kuruc, JD, Gay, CL, Eron, JJ, Margolis, DM, Bosch, RJ, Archin, NM. 2015. Precise Quantitation of the Latent HIV-1 Reservoir: Implications for Eradication Strategies. J Infect Dis 212:1361-1365.

8. Deeks, SG, Autran, B, Berkhout, B, Benkirane, M, Cairns, S, Chomont, N, Chun, TW, Churchill, M, Mascio, MD, Katlama, C, Lafeuillade, A, Landay, A, Lederman, M, Lewin, SR, Maldarelli, F, Margolis, D, Markowitz, M, Martinez-Picado, J, Mullins, JI, Mellors, J, Moreno, S, O’Doherty, U, Palmer, S, Penicaud, MC, Peterlin, M, Poli, G, Routy, JP, Rouzioux, C, Silvestri, G, Stevenson, M, Telenti, A, Lint, CV, Verdin, E, Woolfrey, A, Zaia, J, Barre-Sinoussi, F. 2012. Towards an HIV cure: a global scientific strategy. Nat Rev Immunol 12:607-614.

9. Kim, Y, Anderson, JL, Lewin, SR. 2018. Getting the "Kill" into "Shock and Kill":

Strategies to Eliminate Latent HIV. Cell Host Microbe 23:14-26.

10. Gupta, RK, Abdul-Jawad, S, McCoy, LE, Mok, HP, Peppa, D, Salgado, M, MartinezPicado, J, Nijhuis, M, Wensing, AMJ, Lee, H, Grant, P, Nastouli, E, Lambert, J, Pace, M, Salasc, F, Monit, C, Innes, A, Muir, L, Waters, L, Frater, J, Lever, AML, Edwards, SG, Gabriel, IH, Olavarria, E. 2019. HIV-1 remission following CCR5 $\Delta 32 / \Delta 32$ haematopoietic stem-cell transplantation. Nature

11. Hutter, G, Nowak, D, Mossner, M, Ganepola, S, Mussig, A, Allers, K, Schneider, T, Hofmann, J, Kucherer, C, Blau, O, Blau, IW, Hofmann, WK, Thiel, E. 2009. Long-term control of HIV by CCR5 Delta32/Delta32 stem-cell transplantation. N Engl J Med 360:692-698.

12. Hutter, G. 2016. Stem cell transplantation in strategies for curing HIVIAIDS. AIDS Res Ther 13:31. 
13. Gupta, RK, Peppa, D, Hill, AL, Gálvez, C, Salgado, M, Pace, M, McCoy, LE, Griffith, SA, Thornhill, J, Alrubayyi, A, Huyveneers, LEP, Nastouli, E, Grant, P, Edwards, SG, Innes, AJ, Frater, J, Nijhuis, M, Wensing, AMJ, Martinez-Picado, J, Olavarria, E. 2020. Evidence for HIV-1 cure after CCR5 $\Delta 32 / \Delta 32$ allogeneic haemopoietic stem-cell transplantation 30 months post analytical treatment interruption: a case report. Lancet HIV

14. Henrich, TJ, Hu, Z, Li, JZ, Sciaranghella, G, Busch, MP, Keating, SM, Gallien, S, Lin, NH, Giguel, FF, Lavoie, L, Ho, VT, Armand, P, Soiffer, RJ, Sagar, M, Lacasce, AS, Kuritzkes, DR. 2013. Long-term reduction in peripheral blood HIV type 1 reservoirs following reduced-intensity conditioning allogeneic stem cell transplantation. J Infect Dis 207:1694-1702.

15. Koelsch, KK, Rasmussen, TA, Hey-Nguyen, WJ, Pearson, C, Xu, Y, Bailey, M, Marks, KH, Sasson, SC, Taylor, MS, Tantau, R, Obeid, S, Milner, B, Morrissey, O, Pinto, AN, Suzuki, K, Busch, MP, Keating, SM, Kaiser, P, Yukl, S, Wong, JK, Hiener, BM, Palmer, S, Zaunders, J, Post, JJ, Chan, DJ, Avery, S, Milliken, ST, Kelleher, AD, Lewin, SR, Cooper, DA. 2017. Impact of Allogeneic Hematopoietic Stem Cell Transplantation on the HIV Reservoir and Immune Response in 3 HIV-Infected Individuals. J Acquir Immune Defic Syndr 75:328-337.

16. Salgado, M, Kwon, M, Gálvez, C, Badiola, J, Nijhuis, M, Bandera, A, Balsalobre, P, Miralles, P, Buño, I, Martinez-Laperche, C, Vilaplana, C, Jurado, M, Clotet, B, Wensing, A, Martinez-Picado, J, Diez-Martin, JL, IciStem, C. 2018. Mechanisms That Contribute to a Profound Reduction of the HIV-1 Reservoir After Allogeneic Stem Cell Transplant. Ann Intern Med 169:674-683. 
17. Vincent, K, Roy, DC, Perreault, C. 2011. Next-generation leukemia immunotherapy. Blood 118:2951-2959.

18. Griffioen, M, van Bergen, CA, Falkenburg, JH. 2016. Autosomal Minor Histocompatibility Antigens: How Genetic Variants Create Diversity in Immune Targets. Front Immunol 7:100.

19. Warren, EH, Deeg, HJ. 2013. Dissecting graft-versus-leukemia from graft-versushost-disease using novel strategies. Tissue Antigens 81:183-193.

20. Pitman, MC, Lau, JSY, McMahon, JH, Lewin, SR. 2018. Barriers and strategies to achieve a cure for HIV. Lancet HIV 5:e317-e328.

21. Spierings, E, Kim, YH, Hendriks, M, Borst, E, Sergeant, R, Canossi, A, Oudshoorn, M, Loiseau, P, Dolstra, H, Markiewicz, M, Leffell, MS, Pereira, N, Kircher, B, Turpeinen, H, Eliaou, JF, Gervais, T, Laurin, D, Enczmann, J, Martinetti, M, Thomson, J, Oguz, F, Santarone, S, Partanen, J, Siekiera, U, Alessandrino, EP, Kalayoglu, S, Brand, R, Goulmy, E. 2013. Multicenter analyses demonstrate significant clinical effects of minor histocompatibility antigens on GvHD and GvL after HLA-matched related and unrelated hematopoietic stem cell transplantation. Biol Blood Marrow Transplant 19:1244-1253.

22. Granados, DP, Rodenbrock, A, Laverdure, JP, Côté, C, Caron-Lizotte, O, Carli, C, Pearson, H, Janelle, V, Durette, C, Bonneil, E, Roy, DC, Delisle, JS, Lemieux, S, Thibault, P, Perreault, C. 2016. Proteogenomic-based discovery of minor histocompatibility antigens with suitable features for immunotherapy of hematologic cancers. Leukemia 30:1344-1354. 
23. Lawler, SH, Sussman, RW, Taylor, LL. 1995. Mitochondrial DNA of the Mauritian macaques (Macaca fascicularis): an example of the founder effect. Am J Phys Anthropol 96:133-141.

24. Budde, ML, Wiseman, RW, Karl, JA, Hanczaruk, B, Simen, BB, O'Connor, DH. 2010. Characterization of Mauritian cynomolgus macaque major histocompatibility complex class I haplotypes by high-resolution pyrosequencing. Immunogenetics 62:773-780.

25. O’Connor, SL, Blasky, AJ, Pendley, CJ, Becker, EA, Wiseman, RW, Karl, JA, Hughes, AL, O’Connor, DH. 2007. Comprehensive characterization of MHC class II haplotypes in Mauritian cynomolgus macaques. Immunogenetics 59:449-462.

26. Wiseman, RW, Wojcechowskyj, JA, Greene, JM, Blasky, AJ, Gopon, T, Soma, T, Friedrich, TC, O’Connor, SL, O’Connor, DH. 2007. Simian immunodeficiency virus SIVmac239 infection of major histocompatibility complex-identical cynomolgus macaques from Mauritius. J Virol 81:349-361.

27. Wiseman, RW, Karl, JA, Bohn, PS, Nimityongskul, FA, Starrett, GJ, O'Connor, DH. 2013. Haplessly hoping: macaque major histocompatibility complex made easy. ILAR J 54:196-210.

28. Shimizu, Y, DeMars, R. 1989. Production of human cells expressing individual transferred HLA-A,-B,-C genes using an HLA-A,-B,-C null human cell line. J Immunol $142: 3320-3328$.

29. Burwitz, BJ, Pendley, CJ, Greene, JM, Detmer, AM, Lhost, JJ, Karl, JA, Piaskowski, SM, Rudersdorf, RA, Wallace, LT, Bimber, BN, Loffredo, JT, Cox, DG, Bardet, W, Hildebrand, W, Wiseman, RW, O'Connor, SL, O'Connor, DH. 2009. Mauritian cynomolgus macaques share two exceptionally common major histocompatibility 
complex class I alleles that restrict simian immunodeficiency virus-specific CD8+ T cells. J Virol 83:6011-6019.

30. Bleakley, M, Riddell, SR. 2011. Exploiting T cells specific for human minor histocompatibility antigens for therapy of leukemia. Immunol Cell Biol 89:396-407.

31. den Haan, JM, Bontrop, RE, Pool, J, Sherman, N, Blokland, E, Engelhard, VH, Hunt, DF, Goulmy, E. 1996. Conservation of minor histocompatibility antigens between human and non-human primates. Eur J Immunol 26:2680-2685.

32. Bonhomme, M, Blancher, A, Cuartero, S, Chikhi, L, Crouau-Roy, B. 2008. Origin and number of founders in an introduced insular primate: estimation from nuclear genetic data. Mol Ecol 17:1009-1019.

33. Osada, N, Hettiarachchi, N, Adeyemi Babarinde, I, Saitou, N, Blancher, A. 2015. Whole-genome sequencing of six Mauritian Cynomolgus macaques (Macaca fascicularis) reveals a genome-wide pattern of polymorphisms under extreme population bottleneck. Genome Biol Evol 7:821-830.

34. Olson, ME, Harris, RS, Harki, DA. 2018. APOBEC Enzymes as Targets for Virus and Cancer Therapy. Cell Chem Biol 25:36-49.

35. Hultquist, JF, Lengyel, JA, Refsland, EW, LaRue, RS, Lackey, L, Brown, WL, Harris, RS. 2011. Human and rhesus APOBEC3D, APOBEC3F, APOBEC3G, and APOBEC3H demonstrate a conserved capacity to restrict Vif-deficient HIV-1. J Virol 85:11220-11234.

36. Koning, FA, Newman, EN, Kim, EY, Kunstman, KJ, Wolinsky, SM, Malim, MH. 2009. Defining APOBEC3 expression patterns in human tissues and hematopoietic cell subsets. J Virol 83:9474-9485. 
37. Refsland, EW, Stenglein, MD, Shindo, K, Albin, JS, Brown, WL, Harris, RS. 2010. Quantitative profiling of the full APOBEC3 mRNA repertoire in lymphocytes and tissues: implications for HIV-1 restriction. Nucleic Acids Res 38:4274-4284.

38. Warren, EH, Fujii, N, Akatsuka, Y, Chaney, CN, Mito, JK, Loeb, KR, Gooley, TA, Brown, ML, Koo, KK, Rosinski, KV, Ogawa, S, Matsubara, A, Appelbaum, FR, Riddell, SR. 2010. Therapy of relapsed leukemia after allogeneic hematopoietic cell transplantation with $\mathrm{T}$ cells specific for minor histocompatibility antigens. Blood 115:3869-3878.

39. Allers, K, Hutter, G, Hofmann, J, Loddenkemper, C, Rieger, K, Thiel, E, Schneider, T. 2011. Evidence for the cure of HIV infection by CCR5Delta32/Delta32 stem cell transplantation. Blood 117:2791-2799.

40. Dickinson, AM, Norden, J, Li, S, Hromadnikova, I, Schmid, C, Schmetzer, H, JochemKolb, H. 2017. Graft-versus-Leukemia Effect Following Hematopoietic Stem Cell Transplantation for Leukemia. Front Immunol 8:496.

41. Falkenburg, JH, Warren, EH. 2011. Graft versus leukemia reactivity after allogeneic stem cell transplantation. Biol Blood Marrow Transplant 17:S33-8.

42. Fontaine, P, Roy-Proulx, G, Knafo, L, Baron, C, Roy, DC, Perreault, C. 2001. Adoptive transfer of minor histocompatibility antigen-specific T lymphocytes eradicates leukemia cells without causing graft-versus-host disease. Nat Med 7:789_ 794.

43. Goulmy, E, Gratama, JW, Blokland, E, Zwaan, FE, van Rood, JJ. 1983. A minor transplantation antigen detected by $\mathrm{MHC}$-restricted cytotoxic $\mathrm{T}$ lymphocytes during graft-versus-host disease. Nature 302:159-161. 
44. Janelle, V, Rulleau, C, Del Testa, S, Carli, C, Delisle, JS. 2020. T-Cell

Immunotherapies Targeting Histocompatibility and Tumor Antigens in Hematological Malignancies. Front Immunol 11:276.

45. Li, N, Matte-Martone, C, Zheng, H, Cui, W, Venkatesan, S, Tan, HS, McNiff, J, Demetris, AJ, Roopenian, D, Kaech, S, Shlomchik, WD. 2011. Memory T cells from minor histocompatibility antigen-vaccinated and virus-immune donors improve GVL and immune reconstitution. Blood 118:5965-5976.

46. van der Harst, D, Goulmy, E, Falkenburg, JH, Kooij-Winkelaar, YM, van LuxemburgHeijs, SA, Goselink, HM, Brand, A. 1994. Recognition of minor histocompatibility antigens on lymphocytic and myeloid leukemic cells by cytotoxic T-cell clones. Blood 83:1060-1066.

47. Vincent, K, Hardy, MP, Trofimov, A, Laumont, CM, Sriranganadane, D, HadjMimoune, S, Salem Fourati, I, Soudeyns, H, Thibault, P, Perreault, C. 2014. Rejection of leukemic cells requires antigen-specific T cells with high functional avidity. Biol Blood Marrow Transplant 20:37-45.

48. Margolis, DM, Archin, NM, Cohen, MS, Eron, JJ, Ferrari, G, Garcia, JV, Gay, CL, Goonetilleke, N, Joseph, SB, Swanstrom, R, Turner, AW, Wahl, A. 2020. Curing HIV: Seeking to Target and Clear Persistent Infection. Cell

49. Mitsuyasu, R. 2013. Curing HIV: lessons from cancer therapy. Curr Opin HIV AIDS 8:224-229.

50. Leith, JG, Clark, DA, Matthews, TJ, Rosenthal, KL, Luscher, MA, Barber, BH, MacDonald, KS. 2003. Assessing human alloimmunization as a strategy for inducing 
HIV type 1 neutralizing anti-HLA responses. AIDS Res Hum Retroviruses 19:957965.

51. Mowbray, JF, Underwood, JL, Michel, M, Forbes, PB, Beard, RW. 1987.

Immunisation with paternal lymphocytes in women with recurrent miscarriage. Lancet 2:679-680.

52. Cavalcante, MB, Sarno, M, Araujo Júnior, E, Da Silva Costa, F, Barini, R. 2017. Lymphocyte immunotherapy in the treatment of recurrent miscarriage: systematic review and meta-analysis. Arch Gynecol Obstet 295:511-518.

53. Kling, C, Steinmann, J, Westphal, E, Magez, J, Kabelitz, D. 2006. Adverse effects of intradermal allogeneic lymphocyte immunotherapy: acute reactions and role of autoimmunity. Hum Reprod 21:429-435.

54. Griffioen, M, Honders, MW, van der Meijden, ED, van Luxemburg-Heijs, SA, Lurvink, EG, Kester, MG, van Bergen, CA, Falkenburg, JH. 2012. Identification of 4 novel HLA-B*40:01 restricted minor histocompatibility antigens and their potential as targets for graft-versus-leukemia reactivity. Haematologica 97:1196-1204.

55. Oostvogels, R, Lokhorst, HM, Minnema, MC, van Elk, M, van den Oudenalder, K, Spierings, E, Mutis, T, Spaapen, RM. 2014. Identification of minor histocompatibility antigens based on the 1000 Genomes Project. Haematologica 99:1854-1859.

56. Van Bergen, CA, Rutten, CE, Van Der Meijden, ED, Van Luxemburg-Heijs, SA, Lurvink, EG, Houwing-Duistermaat, JJ, Kester, MG, Mulder, A, Willemze, R, Falkenburg, JH, Griffioen, M. 2010. High-throughput characterization of 10 new minor histocompatibility antigens by whole genome association scanning. Cancer Res 70:9073-9083. 
57. Warren, EH, Greenberg, PD, Riddell, SR. 1998. Cytotoxic T-lymphocyte-defined human minor histocompatibility antigens with a restricted tissue distribution. Blood 91:2197-2207.

58. Laumont, CM, Vincent, K, Hesnard, L, Audemard, É, Bonneil, É, Laverdure, JP, Gendron, P, Courcelles, M, Hardy, MP, Côté, C, Durette, C, St-Pierre, C, Benhammadi, M, Lanoix, J, Vobecky, S, Haddad, E, Lemieux, S, Thibault, P, Perreault, C. 2018. Noncoding regions are the main source of targetable tumorspecific antigens. Sci Transl Med 10

59. Holman, N, Weinfurter, JT, Harsla, TR, Wiseman, RW, Belli, AJ, Michaels, AJ, Reimann, KA, DeMars, RI, Reynolds, MR. 2017. Isolation of a monoclonal antibody from a phage display library binding the rhesus macaque $\mathrm{MHC}$ class I allomorph Mamu-A1*001. PLoS One 12:e0179039.

60. Reynolds, MR, Weiler, AM, Piaskowski, SM, Piatak, MJ, Robertson, HT, Allison, DB, Bett, AJ, Casimiro, DR, Shiver, JW, Wilson, NA, Lifson, JD, Koff, WC, Watkins, DI. 2012. A trivalent recombinant Ad5 gag/pol/nef vaccine fails to protect rhesus macaques from infection or control virus replication after a limiting-dose heterologous SIV challenge. Vaccine 30:4465-4475. 


\section{Figure 1.}
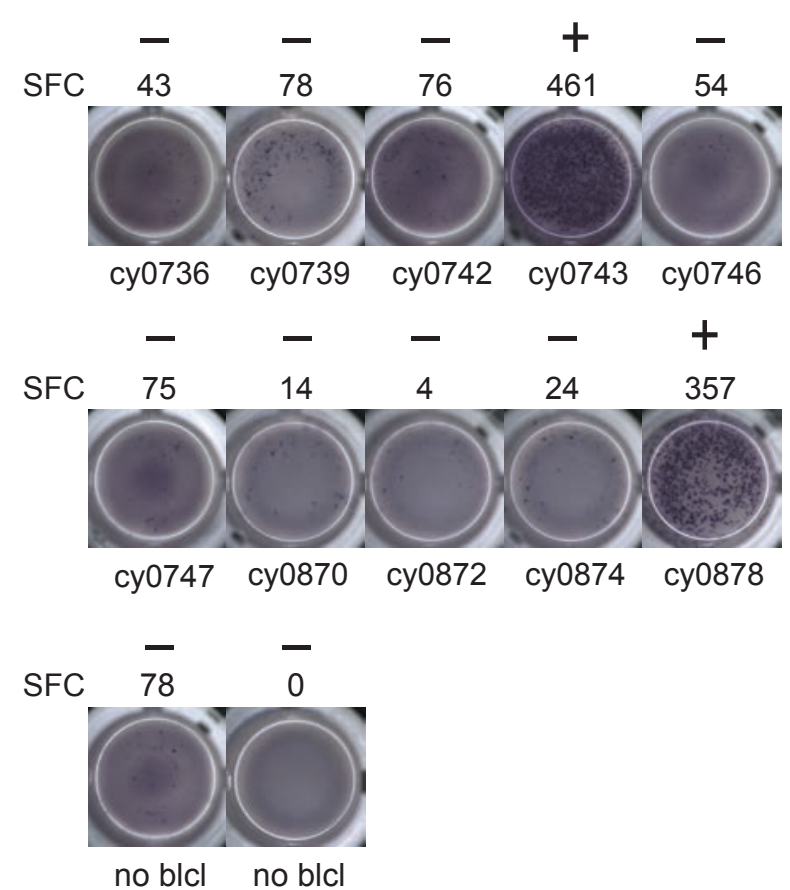

Figure 1. Alloreactive T cell clones differentially recognize allogeneic BLCL. Representative data from T cell clone 11 demonstrating strong reactivity against two of the ten allogeneic BLCLs. Equal numbers of $T$ cells and BLCLs were incubated overnight in IFN-y ELISpot assay. (+) and (-) signify animals that were placed into $\mathrm{mHAg}^{\text {pos }}$ and $\mathrm{mHAg}{ }^{\text {neg }}$ groups for WES segregation analysis, respectively. SFC, spot-forming cell. 


\section{Figure 2.}

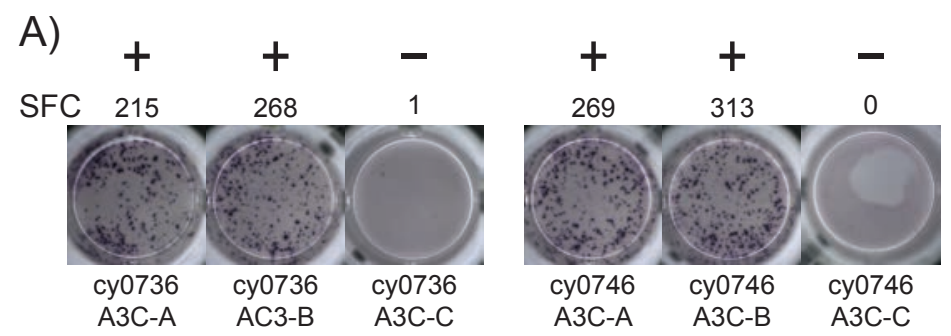

B)
A3C-A
CEDILSPNTDYLVTW
A3C-B
LSPNTDYLVTWYTSW
A3C-C
TDYLVTWYTSWSPCL
Variant CEDILSPNTDYLVTWYTSWSPCL
"wild-type" CEDILSPNTDYRVTWYTSWSPCL

Figure 2. An mHAg-reactive $\mathrm{T}$ cell clone recognizes an amino acid variant in APOBEC3C. (A) T cell clone T11 was incubated with $\mathrm{mHAg}{ }^{\text {neg }} \mathrm{BLCLs}$ from cy0736 (left) or cy0746 (right) pulsed with overlapping 15-mer peptides containing an arginine-to-leucine amino acid change relative to the mHAgneg sequence in an IFN-y ELISpot assay. (B) Sequences of the APOBEC3C (A3C) peptides used to pulse the mHAg ${ }^{\text {neg }} B L C L$ in $(A)$. The variant amino acid is highlighted in bold. The grey box corresponds to the putative region containing the mHAg epitope. $\left(^{+}\right)$and $(-)$signify wells determined to be positive or negative, respectively. SFC, spot-forming cell. 
Figure 3.

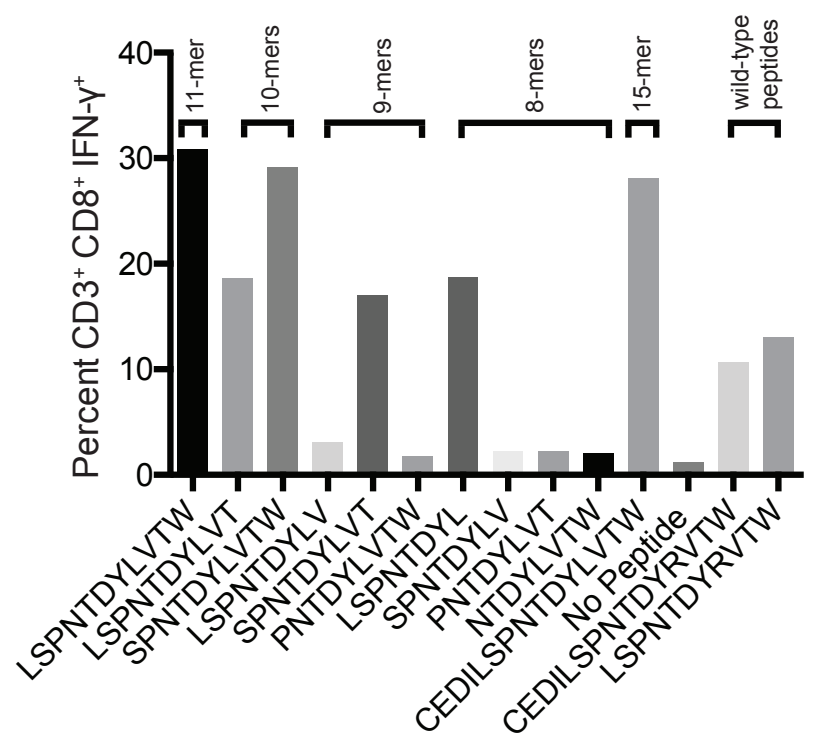

Figure 3. Select peptides corresponding to the $A P O B E C 3 C$ variant stimulate an mHAg-specific T cell line. An APOBEC3C mHAg-specific T cell line was incubated with $\mathrm{mHAg}{ }^{\text {neg }} \mathrm{BLCL}$ pulsed with peptides, including the 11-mer peptide corresponding to the shared region between the 15-mer peptides A3C-A and A3C-B (Figure 2C) and corresponding "wild-type" 15-mer and 11-mer peptides. Unpulsed autologous BLCLs were included as a negative control, and A3C-A peptide-pulsed autologous BLCLs were included as a negative control. Displayed is the percentage of $C D 3^{+} \mathrm{CD} 8^{+} \mathrm{IFN}-\mathrm{\gamma}^{+}$ determined by ICS. 
Figure 4.

A)

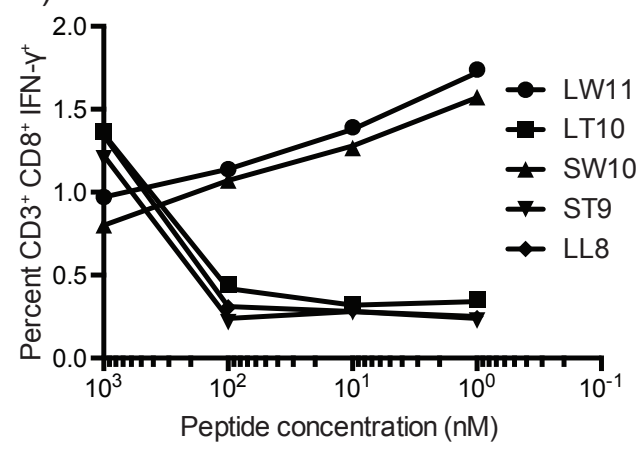

B)

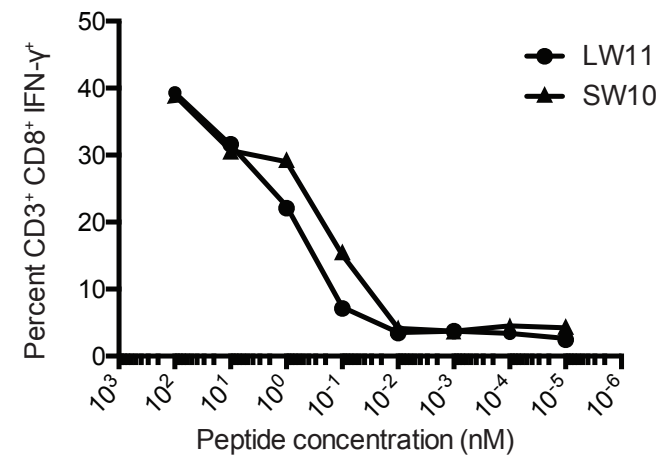

Figure 4. Fine mapping of the mHAg epitope in APOBEC3C. (A) A APOBEC3C mHAg-specific $T$ cell line was incubated with $m H A g^{\text {neg }} B L C L s$ pulsed with serial dilutions of the indicated peptides from $1 \mu \mathrm{M}$ to $1 \mathrm{nM}$. (B) As in (A) with serial dilutions of the peptides SW10 and LW11 from 100nM to $1 \mathrm{fM}$. Displayed is the percentage of CD $3^{+} \mathrm{CD} 8^{+} \mathrm{IFN}-\mathrm{Y}^{+}$ determined by ICS. 


\section{Figure 5.}

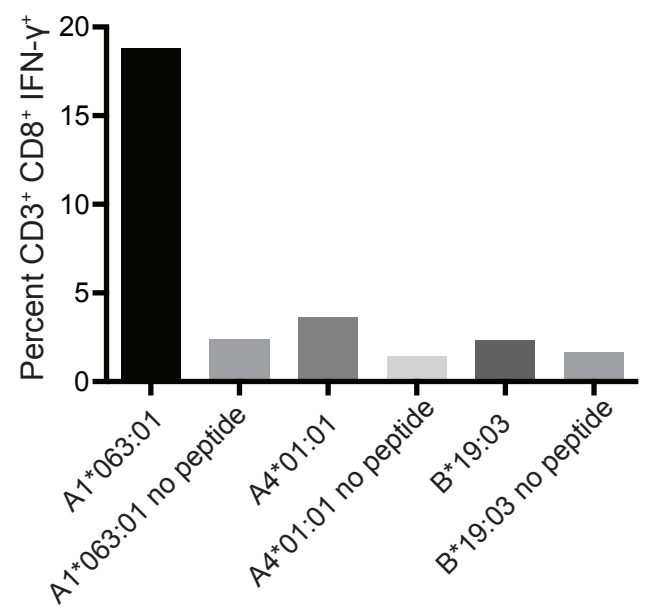

Figure 5. Restriction analysis of the mHAg epitope in APOBEC3C. An APOBEC3C mHAg-specific T cell line was incubated with unpulsed or SW10 peptide-pulsed MHC-I transferents expressing Mafa-A1*063:01, Mafa-A4:01:01, or Mafa-B*19:03. Displayed is the percentage of $\mathrm{CD}^{+} \mathrm{CD} 8^{+} \mathrm{IFN}-\mathrm{Y}^{+}$determined by ICS. 


\section{Figure 6.}
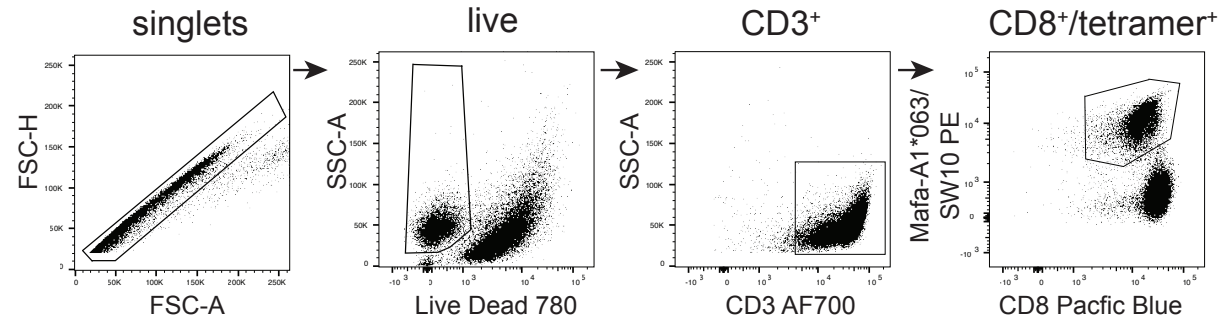

Figure 6. Tetrameric complexes of Mafa-A1*063/SW10 stain APOBEC $3 \mathrm{C}$ SW10-specific CD8+ T cells. An APOBEC 3C mHAg-specific T cell line was stained with PE-conjugated tetrameric complexes of Mafa-A1*063/SW10.

Displayed is the flow cytometric gating strategy for data analysis, progressively selecting signlets, live cells, $\mathrm{CD}^{+}$, and $\mathrm{CD} 8^{+} /$tetramer $^{+}$cells. singlets, live cells, $\mathrm{CD}^{+}$, and $\mathrm{CD} 8^{+} /$tetramer $^{+}$cells. 
Figure 7.

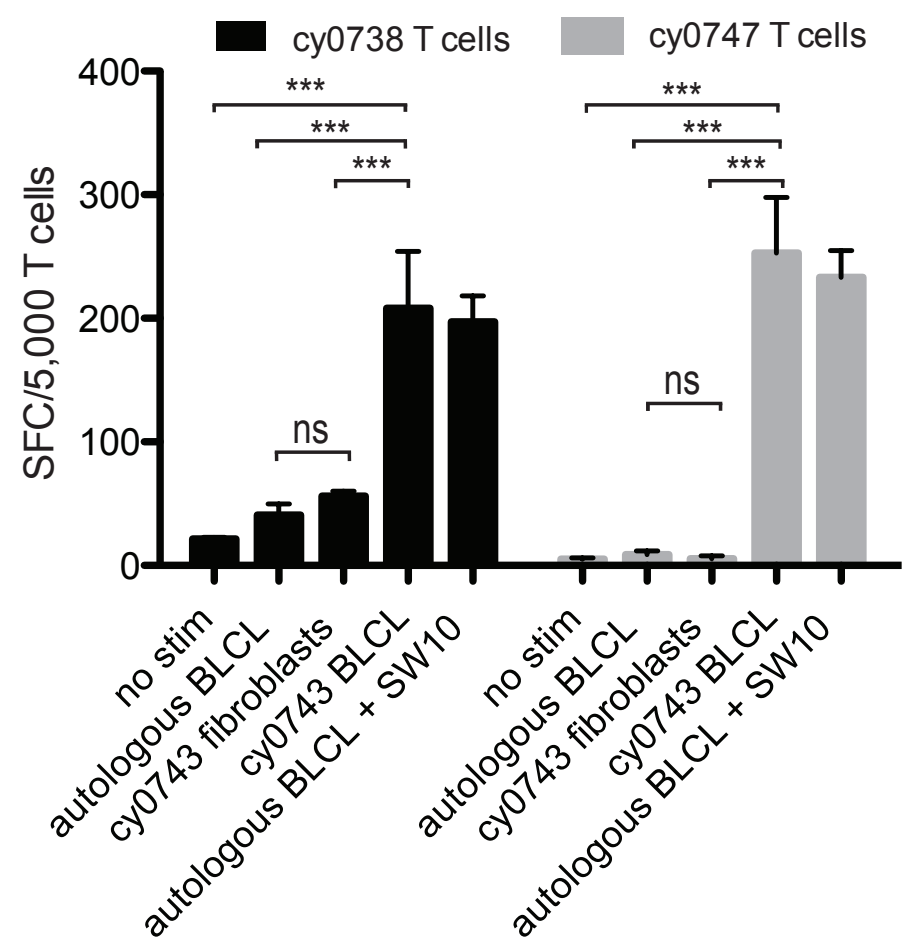

Figure 7. Tissue restriction of the mHAg epitope in APOBEC3C. APOBEC3C SW10-specific T cell lines from MCMs cy0738 and cy0747 were incubated with equal numbers of fibroblasts or BLCLs from the $\mathrm{mHAg}^{\mathrm{pos}}$ animal cy0743 in an IFN-y ELISpot assay. T cells cultured alone or incubated with equal numbers of the corresponding unpulsed autologous BLCLs were included as negative controls, and T cells incubated with equal numbers of the corresponding SW10 peptide-pulsed autologous BLCLs were included as a positive control. Data are shown as a mean \pm SD for each condition. Differences between groups were assessed using a one-way ANOVA with Tukey's test for multiple comparisons. ${ }^{* * *} p<0.0001 ; n s=$ not significant. SFC, spot-forming cell. 